\title{
Development of Sensitive and Specific Analysis of Vildagliptin in Pharmaceutical Formulation by Gas Chromatography-Mass Spectrometry
}

\author{
Ebru Uçaktürk \\ Faculty of Pharmacy, Department of Analytical Chemistry, Hacettepe University, Sihhıye, 06100 Ankara, Turkey \\ Correspondence should be addressed to Ebru Uçaktürk; ebru9679@gmail.com
}

Received 2 September 2015; Accepted 19 October 2015

Academic Editor: Miguel de la Guardia

Copyright () 2015 Ebru Uçaktürk. This is an open access article distributed under the Creative Commons Attribution License, which permits unrestricted use, distribution, and reproduction in any medium, provided the original work is properly cited.

A sensitive and selective gas chromatography-mass spectrometry (GC-MS) method was developed and fully validated for the determination of vildagliptin (VIL) in pharmaceutical formulation. Prior to GC-MS analysis, VIL was efficiently derivatized with MSTFA/ $\mathrm{NH}_{4} \mathrm{I} / \beta$-mercaptoethanol at $60^{\circ} \mathrm{C}$ for $30 \mathrm{~min}$. The obtained O-TMS derivative of VIL was detected by selected ion monitoring mode using the diagnostic ions $\mathrm{m} / \mathrm{z} 223$ and 252. Nandrolone was chosen as internal standard. The GC-MS method was fully validated by the following validation parameters: limit of detection (LOD) and quantitation (LOQ), linearity, precision, accuracy, specificity, stability, robustness, and ruggedness. LOD and LOQ were found to be 1.5 and $3.5 \mathrm{ng} \mathrm{mL}$, respectively. The GC-MS method is linear in the range of $3.5-300 \mathrm{ng} \mathrm{mL}^{-1}$. The intra- and interday precision values were less than $\leq 3.62 \%$. The intra- and interday accuracy values were found in the range of $-0.26-2.06 \%$. Finally, the GC-MS method was successfully applied to determine VIL in pharmaceutical formulation.

\section{Introduction}

Vildagliptin (VIL) [(S)-1-[N-(3-hydroxy-1-adamantyl)glycyl]pyrrolidine-2-carbonitrile] is a new oral antidiabetic drug belonging to the class of dipeptidyl peptidase- 4 inhibitor and is used as treatment of type 2 diabetes. It is given alone or in combination therapy with metformin, sulfonylurea, or thiazolidinedione [1].

VIL (trade names: Galvus, Jalra, and Xiliarx) is approved in many countries worldwide and also a fixed-dose combination with metformin (trade names: Eucreas, Icandra, and Zomarist) is available in the pharmaceutical market $[2,3]$.

Up to date, analysis of VIL alone and together with metformin in pharmaceutical formulations was performed by high performance liquid chromatography (HPLC) and capillary electrophoresis (CE) coupled with ultraviolet (UV) or photodiode array (PDA) detector [4-10]. Specificity of CE and some of HPLC methods was checked using the retention time confirmation and the spectral peak purity of VIL $[4,5]$. VIL gives weak UV absorbance at a maximum wavelength
$207 \mathrm{~nm}$. Therefore, the reported analytical methods have low sensitivity and selectivity.

HPLC is mostly preferred in the quality control of pharmaceutical formulations because of its simplicity, cost effectiveness, and being accessible in most laboratories. Gas chromatography-mass spectrometry (GC-MS) is mostly employed to analyze volatile drugs and residual solvents and to analyze some weak compounds or lack of chromophore groups. GC-MS gives many advantages over HPLC such as high efficiency, sensitivity, specificity, short analysis time, and small sample volume.

In this study we proposed development of a selective, sensitive, and fully validated GC-MS method for the analysis of VIL in pharmaceutical formulation. Herein, VIL was derivatized before GC-MS analysis. Silylation reaction was used for derivatization. Silylation reaction was optimized investigating the following parameters: catalyst, derivatization time, and temperature $[11,12]$. Then, the optimized GC-MS method was fully validated. The developed and validated GC-MS method was applied to determine VIL in tablet formulation. 
This proposed method is important because of the first reported GC-MS method.

\section{Experimental Part}

2.1. Chemicals. VIL was obtained from Central Institute of Hygiene of Turkey. Nandrolone (IS) was kindly provided from Turkish Doping Control Center. Metformin, Nmethyl-N-(trimethylsilyl)trifluoroacetamide (MSTFA), $\beta$ mercaptoethanol, and ammonium iodide $\left(\mathrm{NH}_{4} \mathrm{I}\right)$ were supplied from Sigma-Aldrich. All other chemicals were of analytical reagent grade.

2.2. Instrumentation and GC-MS Conditions. GC-MS analysis was performed on a $6890 \mathrm{~N}$ Agilent GC coupled with $5973 \mathrm{~N}$ mass selective detector. 5\% phenyl methylpolysiloxane capillary column $(30 \mathrm{~m} \times 0.25 \mathrm{~mm}$ i.d. with $0.25 \mu \mathrm{m}$ film thickness, Agilent Technologies, USA) was used for chromatographic analysis. Injection was carried out in split mode with split ratio of $10: 1$ and $1 \mu \mathrm{L}$ of sample was injected to capillary column. The oven temperature was programmed as follows. The initial temperature was set at $200^{\circ} \mathrm{C}$ and then the temperature was increased to $300^{\circ} \mathrm{C}$ at a rate of $25^{\circ} \mathrm{C} \mathrm{min}{ }^{-1}$, and it was held at $300^{\circ} \mathrm{C}$ for $2 \mathrm{~min}$. The total run time is $6 \mathrm{~min}$. The MS was operated in electron impact ionization mode. Selected ion monitoring mode was performed to monitor VIL and IS. The identification masses were $m / z 223$ and 252 for OTMS derivatives of VIL. The ions $\mathrm{m} / z 223$ for VIL and 418 for IS were the most abundant ions. Thus, these ions were selected for quantitation. The temperatures of front inlet, ion source, and interface were 280,230 , and $280^{\circ} \mathrm{C}$, respectively.

2.3. Preparation of Standard Solutions. Stock solution of VIL (500 $\mathrm{ng} \mathrm{mL}^{-1}$ ) was prepared by dissolving the VIL in methanol: water $(50: 50, \mathrm{v}: \mathrm{v})$. In order to prepare standard stock solution of IS (1000 $\left.\mathrm{ng} \mathrm{mL}^{-1}\right)$, appropriate amount of IS was dissolved in methanol. Working solutions of VIL and IS $\left(10 \mathrm{ng} \mathrm{mL}^{-1}\right)$ were prepared by serial dilution of the stock solutions with methanol. Stock and working solutions were kept at $4^{\circ} \mathrm{C}$ for one month.

2.4. Preparation of Derivatization Reagents. In order to prepare the stock solution of MSTFA/ $\mathrm{NH}_{4} \mathrm{I} / \beta$-mercaptoethanol $(100: 2: 6, \mathrm{v}: \mathrm{w}: \mathrm{v}), 100 \mathrm{mg}$ of $\mathrm{NH}_{4} \mathrm{I}$ and $300 \mu \mathrm{L}$ of $\beta$ mercaptoethanol were added to $5 \mathrm{~mL}$ of MSTFA. This stock solution was then diluted to desired concentration $(1000: 2: 6, \mathrm{v}: \mathrm{w}: \mathrm{v})$ with MSTFA. Solutions were stored at $4^{\circ} \mathrm{C}$ in the dark.

2.5. Preparation of Trimethylsilyl (TMS) Ether Derivatives of VIL and IS. To prepare the TMS ether derivatives of VIL and IS, $40 \mu \mathrm{L}$ of derivatization reagent (MSTFA or MSTFA/ $\mathrm{NH}_{4} \mathrm{I} / \beta$-mercaptoethanol mixture) was added to dry residue containing VIL. This solution was left at $60^{\circ} \mathrm{C}$ for $30 \mathrm{~min}$ in a heating block.

2.6. Preparation of the Placebo Samples. The specificity of the GC-MS method was shown to test the placebo tablet containing lactose anhydrous, magnesium stearate, cellulose microcrystalline, and sodium starch glycolate. In order to prepare placebo tablet, the excipients were first taken into $100 \mathrm{~mL}$ flask and $80 \mathrm{~mL}$ of methanol: water $(1: 1, \mathrm{v}: \mathrm{v})$ was added into the flask. The solution was left in the ultrasonic bath for $15 \mathrm{~min}$. Then, it was completed to $100 \mathrm{~mL}$ with mixture of methanol : water $(1: 1, \mathrm{v}: \mathrm{v})$. Finally, it was filtrated by $0.22 \mu \mathrm{m}$ membrane filter.

2.7. Method Validation. In order to show performance of the developed GC-MS method, the GC-MS method was validated by investigating the following parameters: specificity, limit of detection (LOD) and quantification (LOQ), linearity, precision, accuracy, stability, robustness, and ruggedness.

2.7.1. Specificity Test. The GC-MS method was tested if there are any interferences because of the excipients in the pharmaceutical formulation containing VIL active ingredient. Thus, placebo of tablet was prepared as described in Section 2.6 and was analyzed by the GC-MS method. In addition, to evaluate the interference of metformin commonly used medication, metformin standard solution was derivatized as described in Section 2.5 and analyzed by GC-MS. The diagnostic ions for VIL $(m / z 223$ and 252) and IS $(m / z 418)$ were extracted in the chromatograms obtained from placebo sample and metformin.

2.7.2. Limits of the GC-MS Method and Linearity. LOD and LOQ were determined by signal to noise ratio $(\mathrm{S} / \mathrm{N})$ for the two most intense diagnostic ions $(\mathrm{m} / z 223$ and 252). Precision and accuracy at LOQ level were also evaluated. Linearity was investigated in the six concentration levels, 3.5 (LOQ), 10, $50,100,200$, and $300 \mathrm{ng} \mathrm{mL}^{-1}$. Calibration curve was plotted by peak area ratio of VIL to IS versus the concentration of VIL.

2.7.3. Precision and Accuracy. Precision and accuracy were evaluated as intra- and interday. The intraday accuracy and precision were determined by analyzing the standard solutions of VIL prepared in six independent series at three concentration levels $\left(15,150\right.$, and $\left.250 \mathrm{ng} \mathrm{mL}^{-1}\right)$ and these solutions were analysed on the same day.

In the interday accuracy and precision, standard solutions of VIL at three concentration levels $\left(15,150\right.$, and $\left.250 \mathrm{ng} \mathrm{mL}^{-1}\right)$ were prepared for six different days and the solutions were analysed each day. Injection repeatability of the GC-MS method was also performed by injecting ten times of the standard VIL solution at the concentration of $150 \mathrm{ng} \mathrm{mL}^{-1}$. Precision and accuracy were expressed by percent relative standard deviation (RSD) and bias, respectively.

2.7.4. Stability. The stability of the standard stock solutions of VIL (500 $\mathrm{ng} \mathrm{mL}^{-1}$ ) and stability of IS (1000 $\mathrm{n} \mathrm{mL}^{-1}$ ) were tested at $+4^{\circ} \mathrm{C}$ for 30 days. In addition, in order to examine the autosampler stability of O-TMS derivative of VIL, OTMS derivative at three concentration levels $(15,150$, and $250 \mathrm{ng} \mathrm{mL}^{-1}$ ) was placed in autosampler for 12 hours. 
TABLE 1: Selected method parameters and their levels for PlackettBurman experimental design.

\begin{tabular}{lcc}
\hline Selected variables & $\begin{array}{c}\text { Low level } \\
(-)\end{array}$ & $\begin{array}{c}\text { High level } \\
(+)\end{array}$ \\
\hline Analyst & Analyst I & Analyst II \\
Brand of MSTFA & MSTFA I & MSTFA II \\
Derivatization time $(\min )( \pm 5)$ & 25 & 35 \\
Derivatization temperature $\left({ }^{\circ} \mathrm{C}\right)( \pm 5)$ & 55 & 65 \\
\hline
\end{tabular}

TABLE 2: Conducted experimental runs for robustness and ruggedness studies.

\begin{tabular}{lcccc}
\hline \multirow{2}{*}{$\begin{array}{l}\text { Experiment } \\
\text { number }\end{array}$} & \multicolumn{5}{c}{ Selected internal/external variables } \\
& Analyst & $\begin{array}{c}\text { Brand of } \\
\text { MSTFA }\end{array}$ & $\begin{array}{c}\text { Derivatization } \\
\text { time }(\text { min })\end{array}$ & $\begin{array}{c}\text { Derivatization } \\
\text { temperature }\left({ }^{\circ} \mathrm{C}\right)\end{array}$ \\
\hline 1 & $+^{\mathrm{a}}$ & + & $-{ }^{\mathrm{b}}$ & + \\
2 & - & + & + & - \\
3 & + & - & + & + \\
4 & - & + & - & + \\
5 & - & - & + & - \\
6 & - & - & - & + \\
7 & + & - & - & - \\
8 & + & + & - & - \\
9 & + & + & + & + \\
10 & - & + & + & + \\
11 & + & - & + & - \\
12 & - & - & - & + \\
\hline
\end{tabular}

${ }^{\mathrm{a}}$ High level. ${ }^{\mathrm{b}}$ Low level.

After the storage, the standard stock solution of VIL and IS and the O-TMS derivative kept in autosampler for 12 hours were analyzed by GC-MS. The results were compared with the results obtained from freshly prepared solutions.

2.7.5. Robustness and Ruggedness. The robustness and ruggedness of the developed method were evaluated by PlackettBurman experimental design. Selected parameters, levels, and designed experimental matrix were shown in Tables 1 and 2. The peak area ratio of VIL to IS was chosen as response.

2.8. Determination of Vildagliptin in Pharmaceutical Tablet Formulation. Applicability of the developed GC-MS method was assessed by analyzing the tablet formulation containing VIL active ingredient (GALVUS/50 mg VIL/tablet). Ten of the tablets were homogenized in a mortar. An amount of $50 \mathrm{mg}$ was transferred into the $100 \mathrm{~mL}$ volumetric flask. $80 \mathrm{~mL}$ of methanol: water $(1: 1, \mathrm{v}: \mathrm{v})$ was then added to the volumetric flask and left in the ultrasonic bath for $15 \mathrm{~min}$. The solution was made up to the $100 \mathrm{~mL}$ with methanol: water $(1: 1 \mathrm{v}: \mathrm{v})$. Finally, it was filtrated by $0.22 \mu \mathrm{m}$ membrane filter.

\section{Results and Discussion}

VIL does not contain any strong chromophore group. Therefore, it needs to be analyzed HPLC after post- or precolumn derivatization or using MS detectors. Thus, sensitive and specific analysis of VIL would be achieved.

In our study, we aimed to develop a GC-MS method for its analysis. VIL was derivatized prior to GC-MS analysis. Thus, it has thermal stability and/or enough volatility. VIL contains hydroxyl group and - $\mathrm{NH}$ group to be derivatized. In order to derivatize VIL, silylation reaction was tried. MSTFA is used as derivatization reagent. The results showed that only free hydroxyl group of VIL was derivatized and its O-TMS derivative was composed. It is believed that the $-\mathrm{NH}$ group of VIL is sterically hindered so that the silylation reaction is not possible in that side of the molecule. The mass spectrum and fragmentation of O-TMS derivatives of VIL were given in Figure 1.

In order to optimize derivatization reaction, parameters such as catalyst, derivatization time, and temperature were investigated. In the optimization studies, the quantitation ion of VIL $(\mathrm{m} / z 223)$ was monitored and the peak area value of the O-TMS derivative was compared.

In this study, MSTFA was used as silylation reagent and a mixture of $\mathrm{NH}_{4} \mathrm{I} / \beta$-mercaptoethanol was added as base catalyst to increase the yield of the O-TMS derivative. The silylation reaction was performed using MSTFA alone and MSTFA $/ \mathrm{NH}_{4} \mathrm{I} / \beta$-mercaptoethanol with different temperature (room temperature, 60 and $80^{\circ} \mathrm{C}$ ) and time intervals (30 and $60 \mathrm{~min}$ ). The results show that using $\mathrm{NH}_{4} \mathrm{I} / \beta$-mercaptoethanol as base catalyst increases the yield of the O-TMS derivatives of VIL (Figure 2). When the results were compared, the best result was taken at $60^{\circ} \mathrm{C}$ for $30 \mathrm{~min}$.

Nandrolone was selected as IS. It was efficiently derivatized under the optimized derivatization conditions of VIL. The mass spectrometry of IS was given in Figure 1.

\subsection{The GC-MS Method Validation}

3.1.1. Specificity Test. The chromatograms obtained from placebo tablet and metformin standard solution were examined at the retention time of VIL and IS by monitoring the ions of $\mathrm{m} / z$ 223, 252 (diagnostic ions for VIL), and $\mathrm{m} / z$ 418 (diagnostic ion for IS). Any interference because of the excipients and metformin was not observed indicating that the GC-MS method is specific (Figure 3).

3.1.2. Limits of the Method (LOQ and LOD) and Linearity. LOD (S/G: 3) and LOQ (S/G: 10) were determined to be $1.5 \mathrm{ng} \mathrm{mL}^{-1}$ and $3.5 \mathrm{ng} \mathrm{mL}^{-1}$, respectively. Precision and accuracy at LOQ level were found to be $4.03 \%$ and $-1.42 \%$, respectively. The calibration curve ranging $3.5-300 \mathrm{ng} \mathrm{\textrm {mL } ^ { - 1 }}$ had a coefficient of determination $\left(r^{2}\right)$ value $(0.9968 \pm 0.0008)$ greater than 0.99 indicating linear fit over the examined concentration range.

3.1.3. Precision and Accuracy. The results of the intraday accuracy and precision were summarized in Table 3. Values 


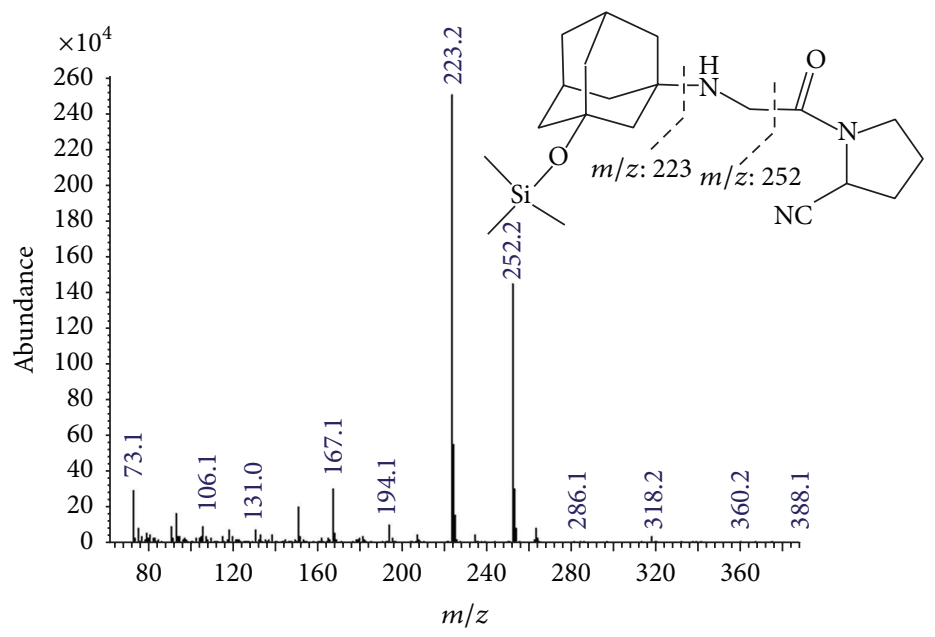

(a)

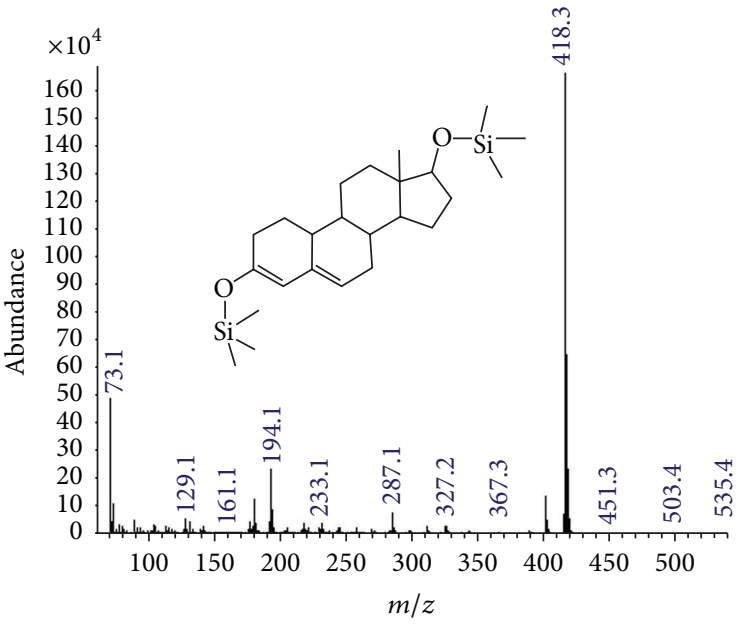

(b)

FIgURE 1: Mass spectrum of the O-TMS derivative of VIL (a) and bis-OTMS derivative of IS (b).

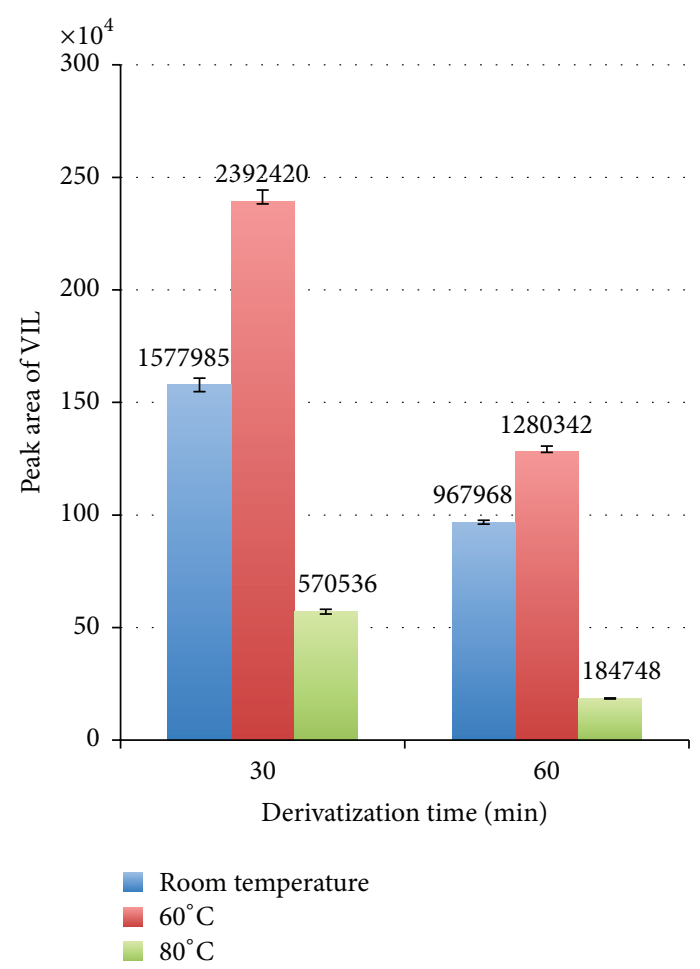

(a)

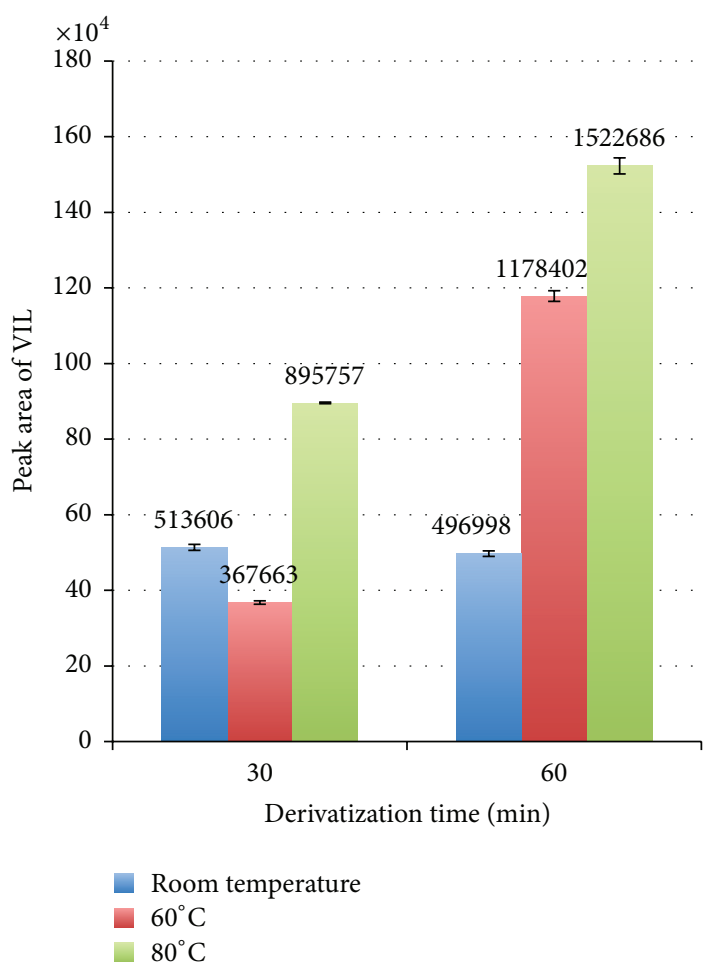

(b)

FIGURE 2: Yield of the derivatization reaction using MSTFA/NH4I/ $\beta$-mercaptoethanol (a) and MSTFA (b) under different temperature and time periods.

TABLE 3: Intra- and interday precision and accuracy results for VIL $(n=6)$.

\begin{tabular}{|c|c|c|c|c|c|c|}
\hline \multirow{2}{*}{ Nominal amount $\left(\mathrm{ng} \mathrm{mL}^{-1}\right)$} & \multicolumn{3}{|c|}{ Interday } & \multicolumn{3}{|c|}{ Intraday } \\
\hline & $X \pm \mathrm{SE}^{\mathrm{a}}$ & Precision $^{\mathrm{b}}(\%)$ & $\operatorname{Accuracy}^{c}(\%)$ & $X \pm \mathrm{SE}^{\mathrm{a}}$ & Precision $^{\mathrm{b}}(\%)$ & $\operatorname{Accuracy}^{\mathrm{c}}(\%)$ \\
\hline 15 & $15.31 \pm 0.19$ & 3.62 & 2.06 & $15.2 \pm 0.22$ & 3.04 & 1.33 \\
\hline 150 & $150.7 \pm 1.68$ & 2.73 & 0.46 & $151.16 \pm 1.49$ & 2.41 & 0.77 \\
\hline 250 & $249.3 \pm 1.87$ & 1.84 & -0.26 & $251.01 \pm 1.20$ & 1.17 & 0.40 \\
\hline
\end{tabular}

${ }^{\mathrm{a}} X \pm$ SE: mean \pm standard error.

${ }^{\mathrm{b}}$ Percent relative standard deviation.

${ }^{\mathrm{c}}$ Bias: [(found - added)/added] $\times 100$. 


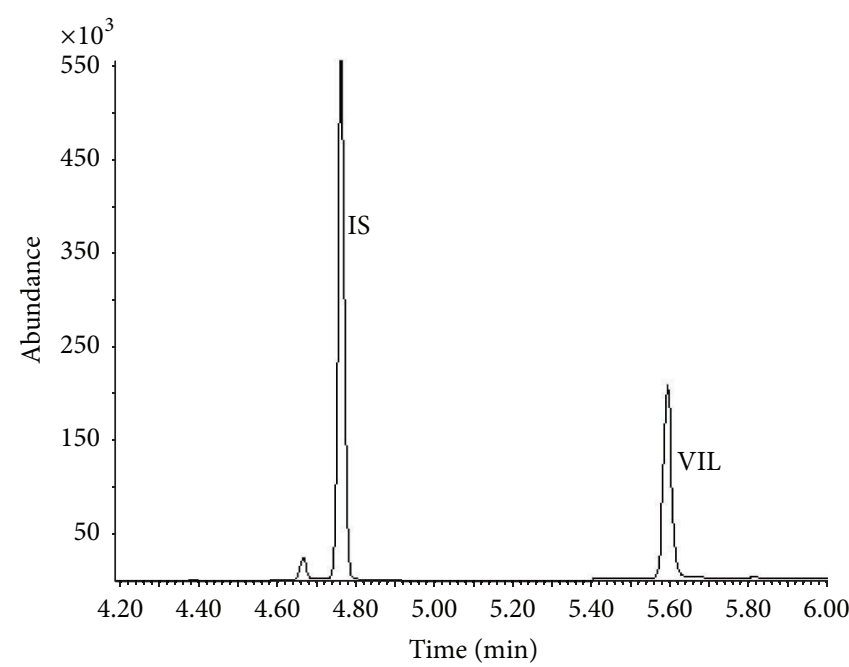

(A)

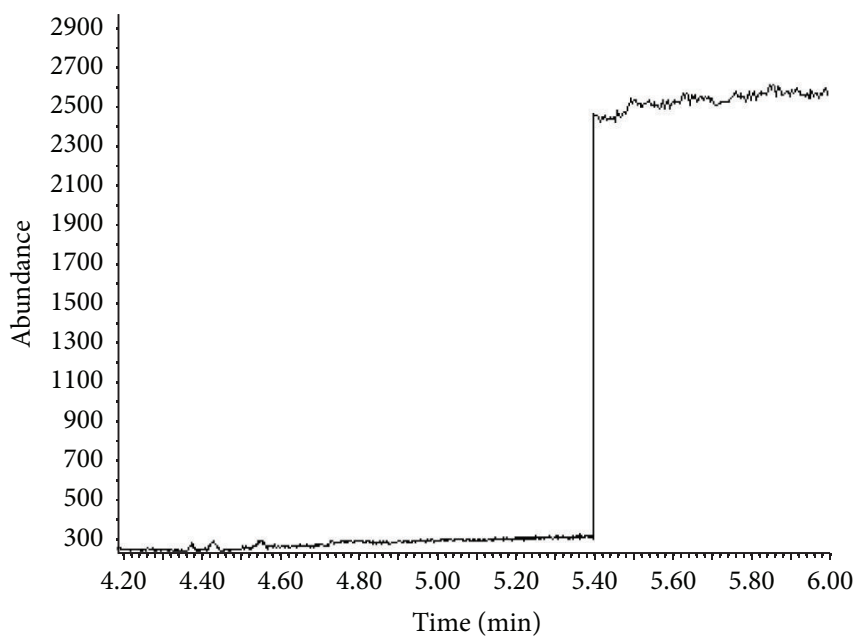

(B)
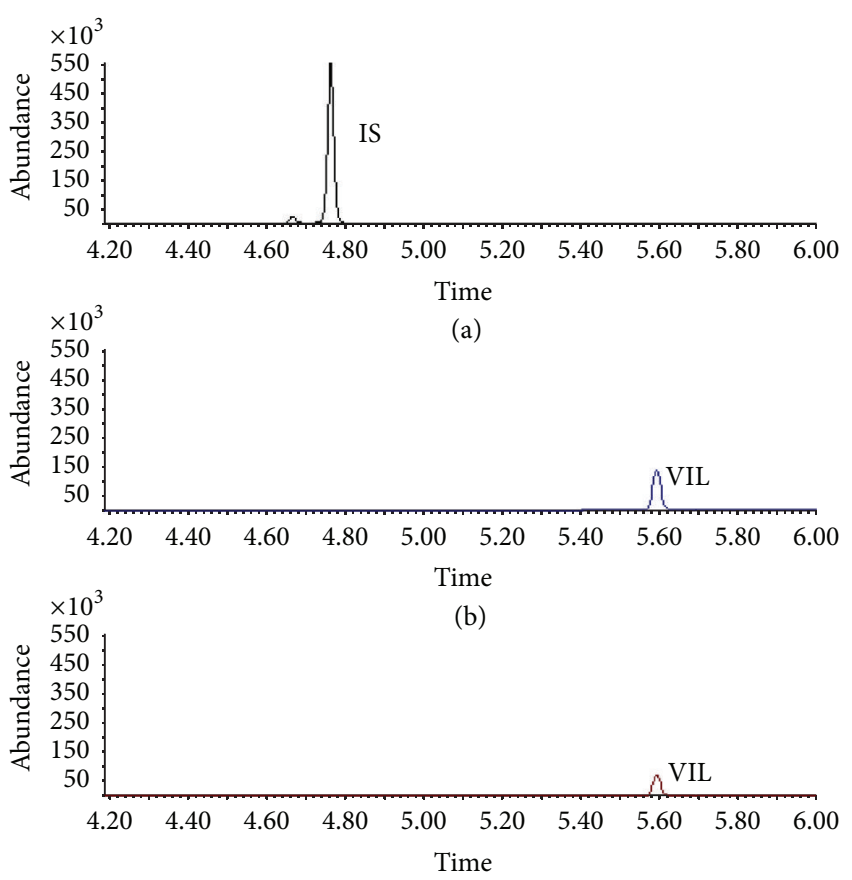

(c)

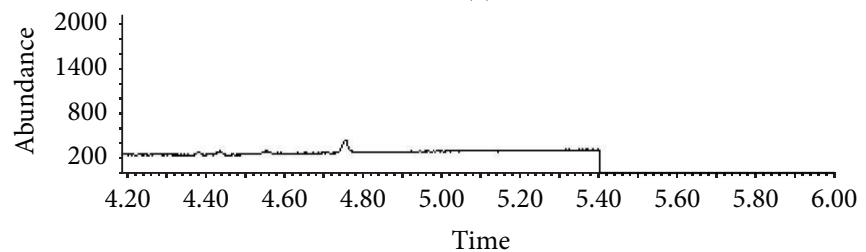

(d)

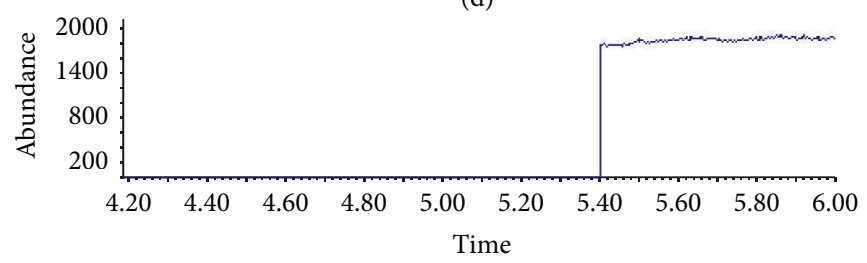

(e)

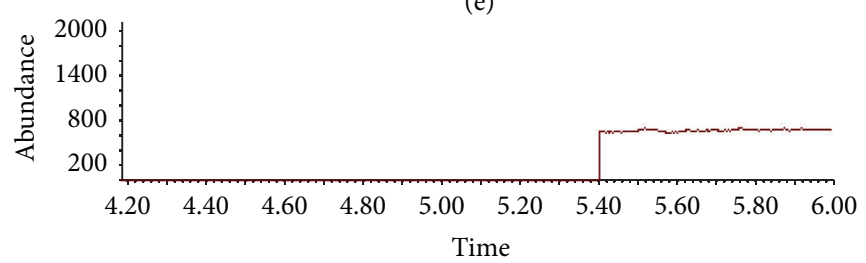

(f)

FIGURE 3: (A) Total ion chromatogram of VIL (100 $\mathrm{ng} \mathrm{mL}^{-1}$ ) and IS. Selected ion chromatograms for $\mathrm{m} / z 418$ (a), 223 (b), and 252 (c) belonging to standard solution containing VIL $\left(100 \mathrm{ng} \mathrm{mL}^{-1}\right)$ and IS. (B) Total ion chromatogram of the placebo tablet. Selected ion chromatograms for $\mathrm{m} / z 418$ (d), 223 (e), and 252 (f) belonging to placebo tablet.

of precision did not exceed $3.62 \%$ and accuracy ranged from -0.26 to $2.06 \%$. Injection repeatability of the GC-MS method was calculated as $1.26 \%$.

3.1.4. Stability. The stability results of the standard stock solutions of VIL ( $500 \mathrm{ng} \mathrm{mL}^{-1}$ ) and IS $\left(1000 \mathrm{ng} \mathrm{mL}^{-1}\right)$ show that there is no significant difference between the storage periods. Therefore, the standard solutions of VIL and IS were prepared monthly in the study. In addition, it was found that the O-TMS derivative of VIL was stabile in autosampler for 12 hours.

3.1.5. Robustness and Ruggedness. In order to evaluate the robustness and ruggedness of the developed method, ANOVA test was used. Thus, the effects of each parameter on the response (peak area ratio of VIL to IS) were determined. 
(response is peak area ratio of VIL/IS, alpha $=0.05$ )

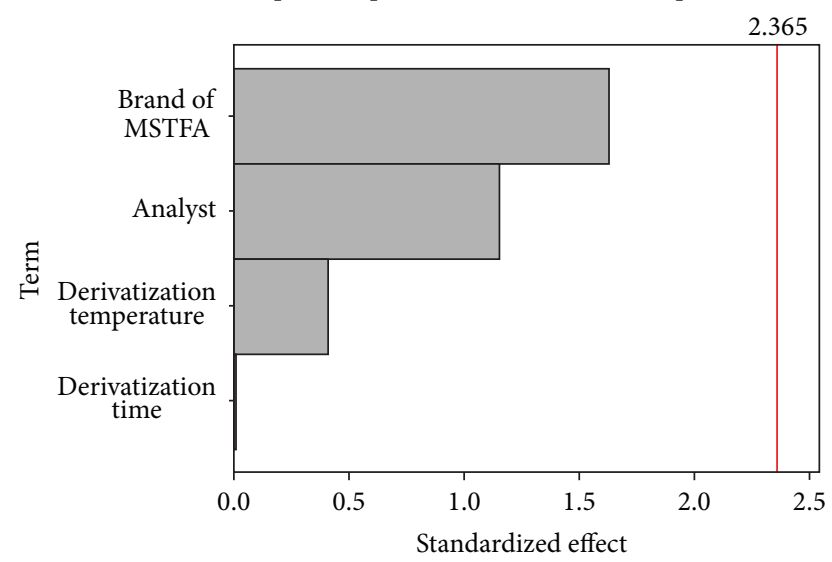

Figure 4: Pareto chart of the standardized effect.

The normal probability plot of the standardized effects was shown in Figure 4. The results showed that the effects of selected parameters on the developed method were not significant $(p=0.228>0.05$ for analyst, $p=0.147>0.05$ for brand of MSTFA, $p=0.996>0.05$ for derivatization time, and $p=0.697>0.05$ for derivatization temperature).

\section{Determination of Vildagliptin in Pharmaceutical Formulations}

In order to show the reliability of the GC-MS method, the developed method was applied to determine VIL in tablet formulation (Galvus $50 \mathrm{mg} /$ Tablet). Sample preparation was described in Sections 2.5 and 2.8 and then these samples were analyzed by GC-MS method. The content of the tablet was calculated from the calibration curve. The amount of VIL in tablet was found to be $50.12 \pm 0.35$ (mean \pm S.E., $1.71 \%$ RSD) indicating that the proposed GC-MS method was reliable for quantitation of VIL in tablet.

\section{Conclusion}

In this study, we reported a GC-MS method for the determination of VIL for the first time. VIL was efficiently derivatized with MSTFA/ $\mathrm{NH}_{4} \mathrm{I} / \beta$-mercaptoethanol and converted into the O-TMS derivative. Derivatization procedure is simple and one-step. The total analysis time takes $6 \mathrm{~min}$ offering the high throughput analysis of VIL. The ions $\mathrm{m} / z 223$ and 252 can be effectively used as diagnostic ions for the determination of VIL. Thus, the proposed GC-MS method would be much more specific and sensitive than the other reported methods using UV or PDA detection [4-10]. The developed GCMS method can be considered sensitive, selective, precise, accurate, robust, and rugged according to the validation studies. The method was suitably used for determination of VIL in tablet formulation. This GC-MS method may be used for the routine determination of VIL in biological samples.

\section{Conflict of Interests}

The author declares that there is no conflict of interests regarding the publication of this paper.

\section{Acknowledgments}

The author would like to thank Turkish Doping Control Center and the Central Institute of Hygiene of Turkey (Ankara, Turkey) for providing internal standard and vildagliptin standard, respectively.

\section{References}

[1] J. D. Croxtall and S. J. Keam, "Vildagliptin: a review of its use in the management of type 2 diabetes mellitus," Drugs, vol. 68, no. 16, pp. 2387-2409, 2008.

[2] G. M. Keating, "Vildagliptin: a review of its use in type 2 diabetes mellitus," Drugs, vol. 70, no. 16, pp. 2089-2112, 2010.

[3] T. Forst and P. Bramlage, "Vildagliptin, a DPP-4 inhibitor for the twice-daily treatment of type 2 diabetes mellitus with or without metformin," Expert Opinion on Pharmacotherapy, vol. 15, no. 9, pp. 1299-1313, 2014.

[4] A. M. Kashid, D. A. Ghorpade, P. P. Toranmal, and S. C. Dhawale, "Development and validation of reversed phase HPLC method for the determination of vildagliptin using an experimental design," Journal of Analytical Chemistry, vol. 70, no. 4 , pp. 510-515, 2015.

[5] A. T. Barden, B. L. Piccoli, N. M. Volpato, E. E. S. Schapoval, and M. Steppe, "Capillary zone electrophoresis for determination of vildagliptin (a DPP-4 inhibitor) in pharmaceutical formulation and comparative study with HPLC," Pharmazie, vol. 69, no. 2, pp. 86-91, 2014.

[6] A. T. Barden, B. L. Piccoli, N. M. Volpato, and M. Steppe, "A simultaneous assay method using capillary zone electrophoresis for a fixed dose combination of vildagliptin and metformin hydrochloride in coated tablets," Analytical Methods, vol. 5, no. 20, pp. 5701-5708, 2013.

[7] N. Satheeshkumar, M. Pradeepkumar, S. Shanthikumar, and V. J. Rao, "Development of validated stability indicating assay method for simultaneous estimation of metformin hydrochloride and vildagliptin by RP-HPLC," Drug Research, vol. 64, no. 3, pp. 124-129, 2014.

[8] S. Pednekar, R. Lokhande, R. Sutar, S. Kolhal, S. Surve, and S. Gudekar, "Simultaneous determination of metformin, Sitagliptin, Saxagliptin, Linagliptin and vildagliptin in multicomponent pharmaceutical preparations by RP-HPLC,' International Journal of Pharmaceutical Sciences Review and Research, vol. 28, pp. 128-133, 2014.

[9] M. Attimarad, S. H. Nagaraja, B. E. Aldhubaib, A. Nair, and K. N. Venugopala, "Simultaneous determination of metformin and three gliptins in pharmaceutical formulations using RP HPLC: application to stability studies on Linagliptin tablet formulation," Indian Journal of Pharmaceutical Education and Research, vol. 48, no. 4, pp. 45-53, 2014.

[10] T. Boovizhikannan and V. K. Palanirajan, "RP-HPLC determination of vildagliptin in pure and in tablet formulation," Journal of Pharmacy Research, vol. 7, no. 1, pp. 113-116, 2013.

[11] E. Uçaktürk, "Development of a gas chromatography-mass spectrometry method for the analysis of sitagliptin in human 
urine," Journal of Pharmaceutical and Biomedical Analysis, vol. 74, pp. 71-76, 2013.

[12] E. Uçaktürk, "The development and validation of a gas chromatography-mass spectrometry method for the determination of metformin in human plasma," Analytical Methods, vol. 5, no. 18, pp. 4723-4730, 2013. 

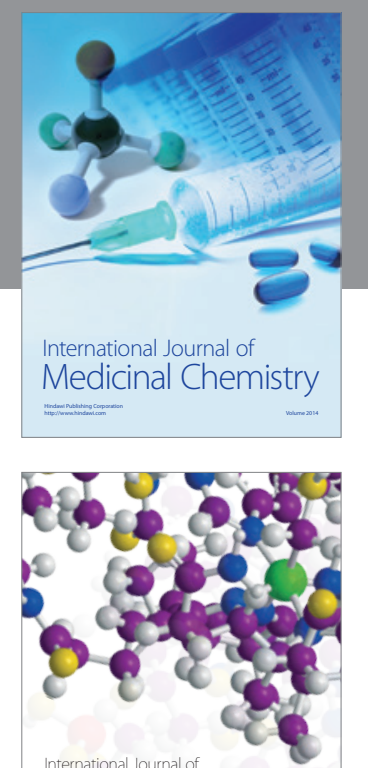

\section{Carbohydrate} Chemistry

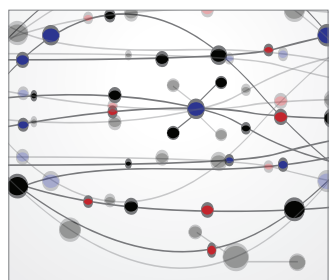

The Scientific World Journal
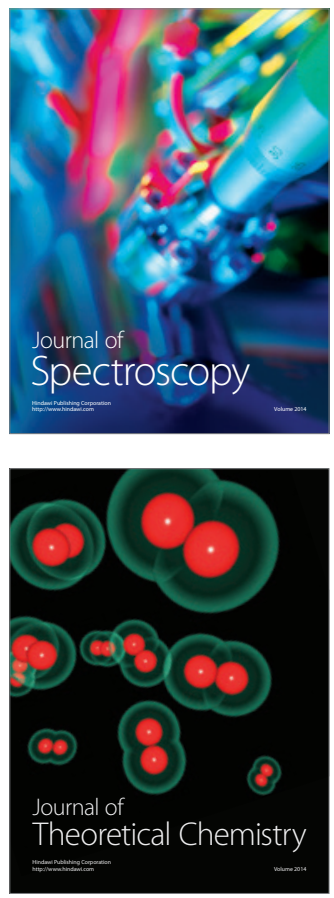
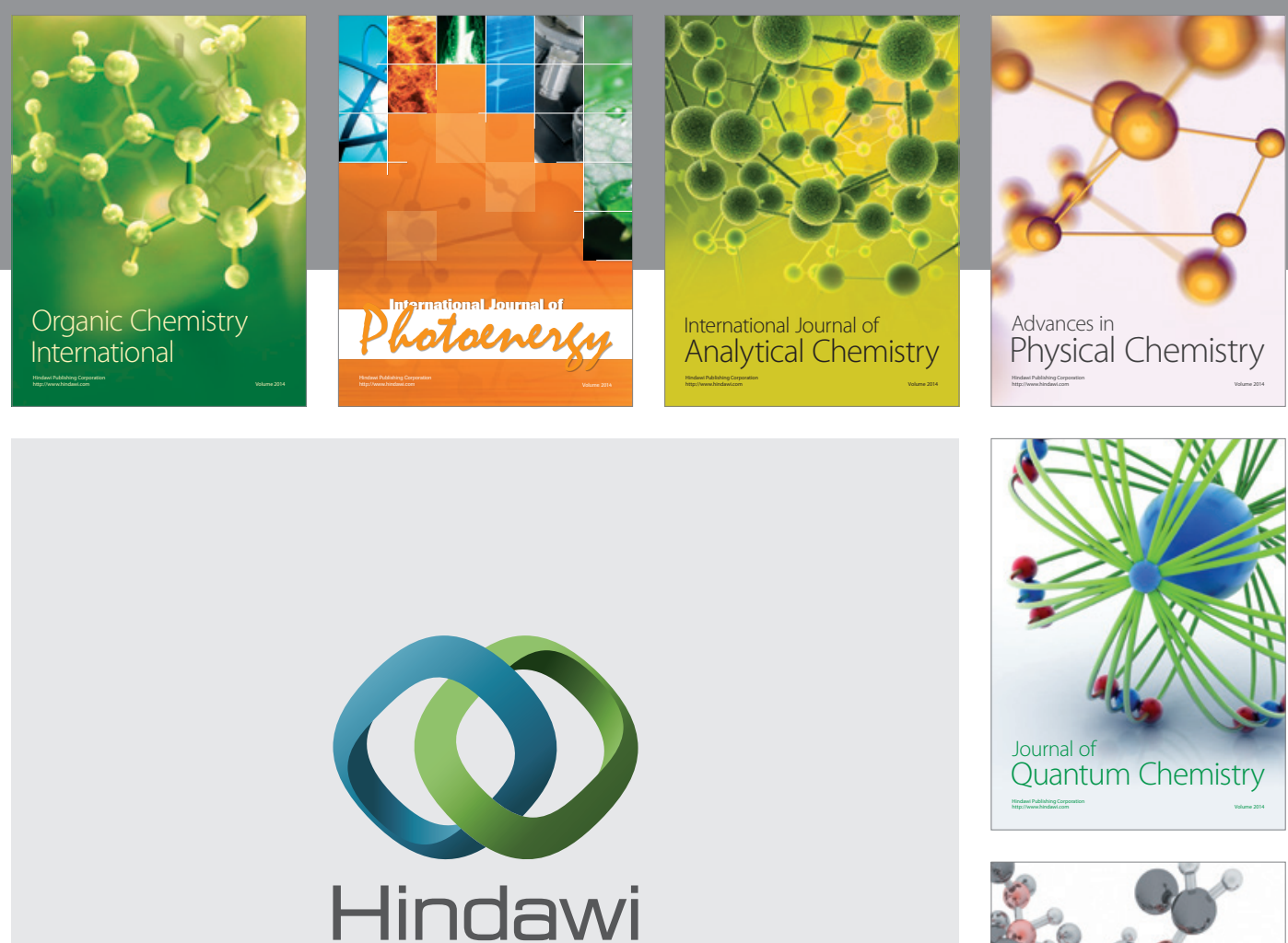

Submit your manuscripts at

http://www.hindawi.com

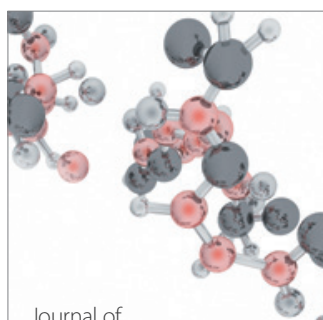

Analytical Methods

in Chemistry

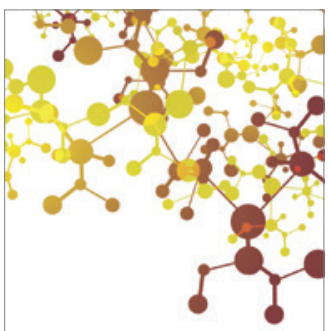

Journal of

Applied Chemistry

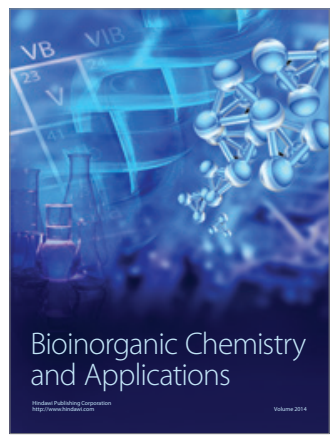

Inorganic Chemistry
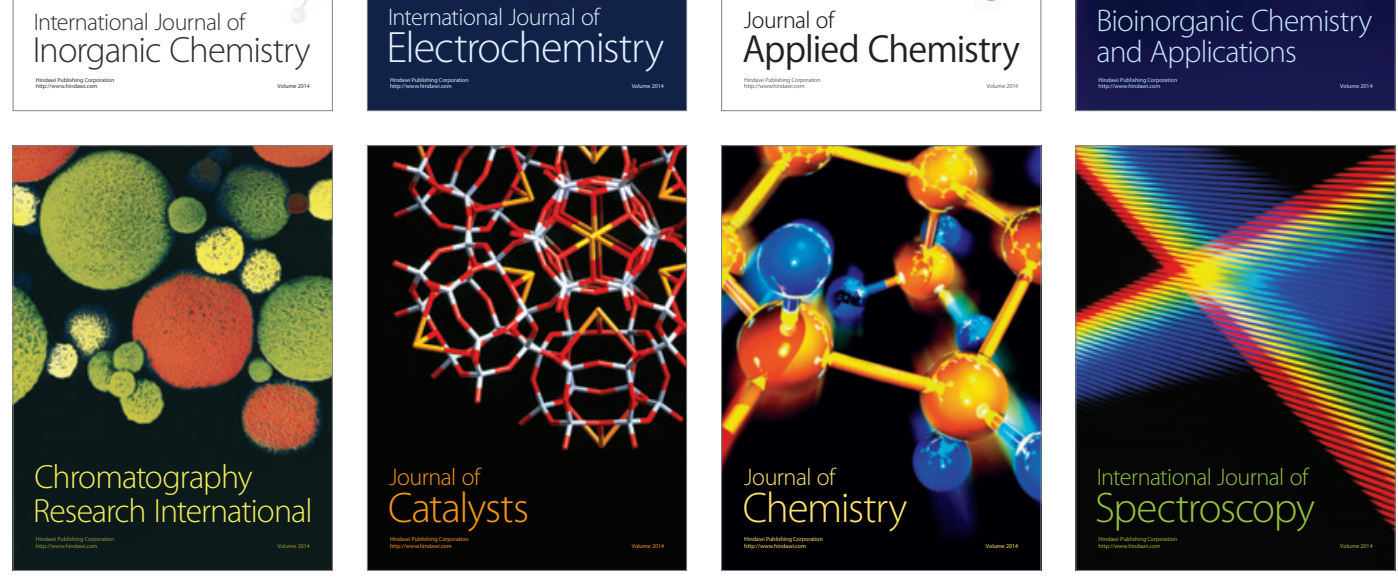